\title{
Prolactin Up-Regulates Cathepsin B and D Expression in Minor Salivary Glands of Patients with Sjögren's Syndrome
}

\author{
Serge Steinfeld, Arielle Maho, Carole Chaboteaux, Philippe Daelemans, \\ Roland Pochet, Thierry Appelboom, and Robert Kiss
}

\author{
Divisions of Rheumatology (SS, TA) and Stomatology (PD), Erasme University Hospital, IRIBHN (AM), Laboratory of \\ Histopathology (CC, RP, RK), Faculty of Medicine, Université Libre de Bruxelles, Brussels, Belgium
}

\begin{abstract}
SUMMARY: Various proteases are expressed in the minor salivary glands (MSG) of patients with Sjögren's syndrome (SS), and as we have already shown, prolactin is neosynthesized in the acinar cells of patients with SS. The present study aims to characterize the influence of PRL on the expression of cathepsin B and D in the MSG of patients with SS. Cathepsin B and D expression was investigated immunohistochemically in MSG of 30 patients with SS and 15 healthy volunteers. The presence of cathepsin B and D mRNAs was checked in three SS patients and three control subjects by means of reverse transcriptionpolymerase chain reaction (RT-PCR). The specificity of the anti-cathepsin B and D antibodies used for the immunohistochemistry was checked by means of western blotting analysis. The influence of prolactin on the immunohistochemical expression of cathepsin B and D was quantitatively assayed by computer-assisted microscopy at three different doses (5, 50, and 500 ng/ml) on eight MSGs (four control subjects and four patients with SS) maintained ex vivo under organotypic cultures. This influence was also investigated at the mRNA level. Whereas cathepsin B immunopositivity was absent from glandular epithelial cells of healthy subjects and only slightly present in SS patients, cathepsin D immunoreactivity was considerably greater $(p<0.0001)$ in both the acini and the ducts of patients with SS as compared with control subjects. Cathepsin B, but not D, was also expressed in about $20 \%$ of infiltrating mononuclear cells of SS patients. Treatment of both healthy and SS minor salivary glands with PRL significantly $(p<0.05$ to $p<0.0001)$ enhanced cathepsin B and D expression in acinar and ductal cells at both protein and mRNA levels. PRL produced locally in MSGs of SS patients, but not those of healthy subjects, could play a role in the pathogenesis of Sjögren's syndrome, if only through the activation of proteolytic activity on the part of cathepsins B and D. (Lab Invest 2000, 80:1711-1720).
\end{abstract}

\begin{abstract}
S jögren's syndrome (SS) is a chronic autoimmune $\int$ disease characterized by lymphocytic infiltration and destruction of salivary and lacrimal glands leading to the loss of secretory function with clinical presentation of xerostomia and dry eyes (Fox and Kang, 1992). Sjögren's syndrome is associated with the production of autoantibodies because B cell activation is a consistent immunoregulatory abnormality. The events that lead to SS autoimmune responses are not clearly established, but genetic, endocrine, and viral factors are relevant (Fox and Kang, 1992). The development of SS is strongly associated with major histocompatibility complex (MHC) class II genes and, particularly, human leukocyte antigen (HLA)-DR and -DQ alleles (Foster et al, 1993; Kerttula et al, 1996; Reveille and Arnett, 1992; Rischmueller et al, 1998). These molecules play a central role in the initiation and
\end{abstract}

Received July 7, 2000.

This work has been carried out on the basis of a grant (3.4551.01) awarded by the Fonds de la Recherche Scientifique Médicale (FRSM, Belgium). RK is a Senior Research Associate with the Fonds National de la Recherche Scientifique (FNRS, Belgium).

Address reprint requests to: Dr. Robert Kiss, Laboratory of Histopathology, Faculty of Medicine, Université Libre de Bruxelles, 808 Route de Lennik, 1070 Brussels, Belgium. Fax: 32255562 85; E-mail: rkiss@med.ulb.ac.be maintenance of immune responses in that they present proteolytically processed antigen peptides to CD4 $T$ lymphocytes, which are the most frequent infiltrating cells in SS (Adamson et al, 1983).

Cathepsin $\mathrm{D}$ is an aspartic protease present in most of the cells of many species, including humans (Scezi, 1992), and seems to play an important role in the processing of antigens into lysosomes (Davidson and Watts, 1989). Cathepsin B is a cysteine protease with both exo- and endopeptidase activity (Chapman et al, 1997). Cathepsin $D$ has been shown to be capable of activating cathepsin $\mathrm{B}$ by the cleavage of the procathepsin polypeptide (Nishimura et al, 1988). Cathepsins $B$ and $D$ are involved in several of the pathways leading to apoptosis (Deiss et al, 1996; Roberts et al, 1999).

Salivary epithelial cells from patients with SS express MHC class II molecules (Fox et al, 1986a). Recent studies (Kaslow et al, 1998; Yang et al, 1999) suggest that acinar epithelial cells, induced to express MHC class II molecules, function as autoantigen processing and presenting cells. Cathepsin B and D are antigen-processing enzymes (Mizuochi et al, 1994). Furthermore, both cathepsin $B$ and $D$ are involved in a proteolytic cascade resulting in activation of inactive prometalloproteinases to form active metalloproteinases (Mort and Buttle, 1997). Elevated matrix metallo- 
proteinase (MMP-2, -9) activity has been reported in human salivary gland cell lines treated with interferon- $\gamma$ (Wu et al, 1997). In addition, Azuma et al (1997) have shown that various cytokines, including tumor necrosis factor- $\alpha$ (TNF- $\alpha$ ) and interleukin-1 $\beta$ $(\mathrm{IL}-1 \beta)$, contribute to the destruction of basal membrane of labial salivary acinar epithelial cells from SS patients, acting in part through the activation of MMP-2 proteolytic activity.

In a previous study (Steinfeld et al, 2000), we report the neosynthesis and overexpression of a big prolactin (60 kDa) in the glandular epithelial cells of minor salivary glands of patients with SS. We and others (Garcia-Caballero et al, 1996; Steinfeld et al, 2000) have also shown that PRL-receptor was expressed in ductal epithelial cells leading to a paracrine action of PRL. Furthermore, the presence of anti-Ro and anti-La antibodies was associated with a higher percentage of $\mathrm{PRL}$ in acinar epihelial cells suggesting a role for PRL in inducing autoantibody production (Steinfeld et al, 2000). Because cytokines, including PRL, have been shown to stimulate the synthesis and production of certain proteases in various cell types (Nagafuchi et al, 1999), we investigated whether PRL could modulate cathepsin B and D expression in the minor salivary glands of patients with SS. We thus made use of computer-assisted microscopy to quantitatively determine the immunohistochemical expression of cathepsins B and D in the ducts and acini of minor salivary glands biopsied in SS patients as opposed to healthy volunteers and maintained ex vivo under organotypic culture conditions. Cathepsin B and D mRNAs were evidenced in the minor salivary glands (MSGs) of the patients with SS and the control subjects by means of RT-PCR.

\section{Results}

\section{Characterization of Cathepsin B and D Expression in MSGs of Patients with SS and Control Subjects}

Cathepsin B appeared not to be expressed in minor salivary glands of SS patients and healthy subjects when the evaluation of any expression was carried out semiquantitatively on archive materials, ie, MSGs fixed in formalin, embedded in paraffin, and used for routine diagnosis (Table 1 ). In contrast, acini in the MSGs used for the organotypic cultures exhibited a significant level of cathepsin B expression (quantified in Fig. 1). Infiltrating mononuclear cells were slightly immunoreactive to cathepsin B in MSGs of patients with SS (data not shown).

Cathepsin D immunoreactivity was considerably greater $(p<0.0001)$ in the acinar and ductal epithelial cells of SS minor salivary glands than in control glands (Table 1). Both normal and pathological epithelial cells showed a granular pattern, thus indicating the lysosomal localization of cathepsin D (Fig. 2). Cathepsin D was absent from infiltrating mononuclear cells (data not shown).
Table 1. Percentage of Immunopositive Cells and Staining Intensity in Salivary Glands from Control Subjects and Patients with SS

\begin{tabular}{cccccc}
\hline & \multicolumn{2}{c}{$\begin{array}{c}\text { Control } \\
\text { subjects }\end{array}$} & & \multicolumn{2}{c}{ SS patients } \\
\cline { 2 - 3 } \cline { 5 - 6 } & Acini & Ducts & & Acini & Ducts \\
\hline $\begin{array}{c}\text { Cathepsin B } \\
\mathrm{LI}^{a}\end{array}$ & - & - & & + & ++ \\
$\mathrm{SI}^{b}$ & 0 & 0 & & 1 & 1 \\
Cathepsin D & & & & \\
$\mathrm{LI}^{a}$ & + & + & $++^{* *}$ & $++^{* *}$ \\
$\mathrm{SI}^{b}$ & 1 & 1 & & $2^{* * *}$ \\
\hline
\end{tabular}

a The percentage of positive cells (LI) was subjectively divided into four grades: no positive cells $=-; 0 \%$ to $25 \%$ positive cells $=+; 26 \%$ to $50 \%$ positive cells $=++$; and $>50 \%$ positive cells $=+++$.

${ }^{b}$ Absence of staining (SI) or staining equivalent to background staining in the negative control was graded 0 , weak to moderate staining was graded 1 , and intense staining was graded 2 .

${ }^{* \star}=p<0.01 ;{ }^{\star \star *}=p<0.0001$ (Pearson $\left.\chi^{2}\right)$.

\section{Characterization of the Specificities of the Anticathepsin $B$ and $D$ Antibodies and Validation of the Computer-Assisted Microscope Analysis}

The specificities of the anticathepsin B and D antibodies that we used throughout were checked by means of western blotting analysis. We employed three human cancer cell lines (the breast T47-D and MCF-7 and the colon LoVo models) that we knew to express cathepsins B and D, but at different intensities. The upper part of Figure 3 shows that the anticathepsin $D$ antibody recognizes both the inactive $52 \mathrm{kDa}$ procathepsin D and the active $34 \mathrm{kDa}$ cathepsin D, whereas the anticathepsin $\mathrm{B}$ antibody recognizes the active $31 \mathrm{kDa}$ cathepsin $\mathrm{B}$. These data thus indicate that the antibodies used in the present study exhibited good specificities against cathepsins $B$ and $D$, the proteins under investigation.

The data obtained by means of western blotting analysis (upper part of Fig. 3) fit in perfectly with those obtained by means of computer-assisted microscope analysis (lower part of Fig. 3). Indeed, the intensities of the cathepsin D bands (upper left part of Fig. 3) in the western blotting analysis were higher than those for the cathepsin B bands (upper right part of Fig. 3), and the computer-assisted microscope analysis also revealed that the cathepsin $D$ expression (assessed by means of the mean optical density variable), ie, the open bars in the lower part of Figure 3, was significantly higher $(p<0.001$ in the LoVo and MCF-7 cell lines and $p<0.0001$ in the T47-D cell line) than that of cathepsin B (hatched bars). In the same vein, the intensity of the cathepsin $\mathrm{D}$ bands appeared stronger in the MCF-7 and T47-D cell lines than in the LoVo cell line. Very similar data were provided by the computerassisted microscope analysis. All these data therefore validate the use of the computer-assisted microscope analysis of the immunohistochemical expression of cathepsin B and D in the organotypic cultures of minor salivary glands. 


\section{ст Cathepsin B ss}
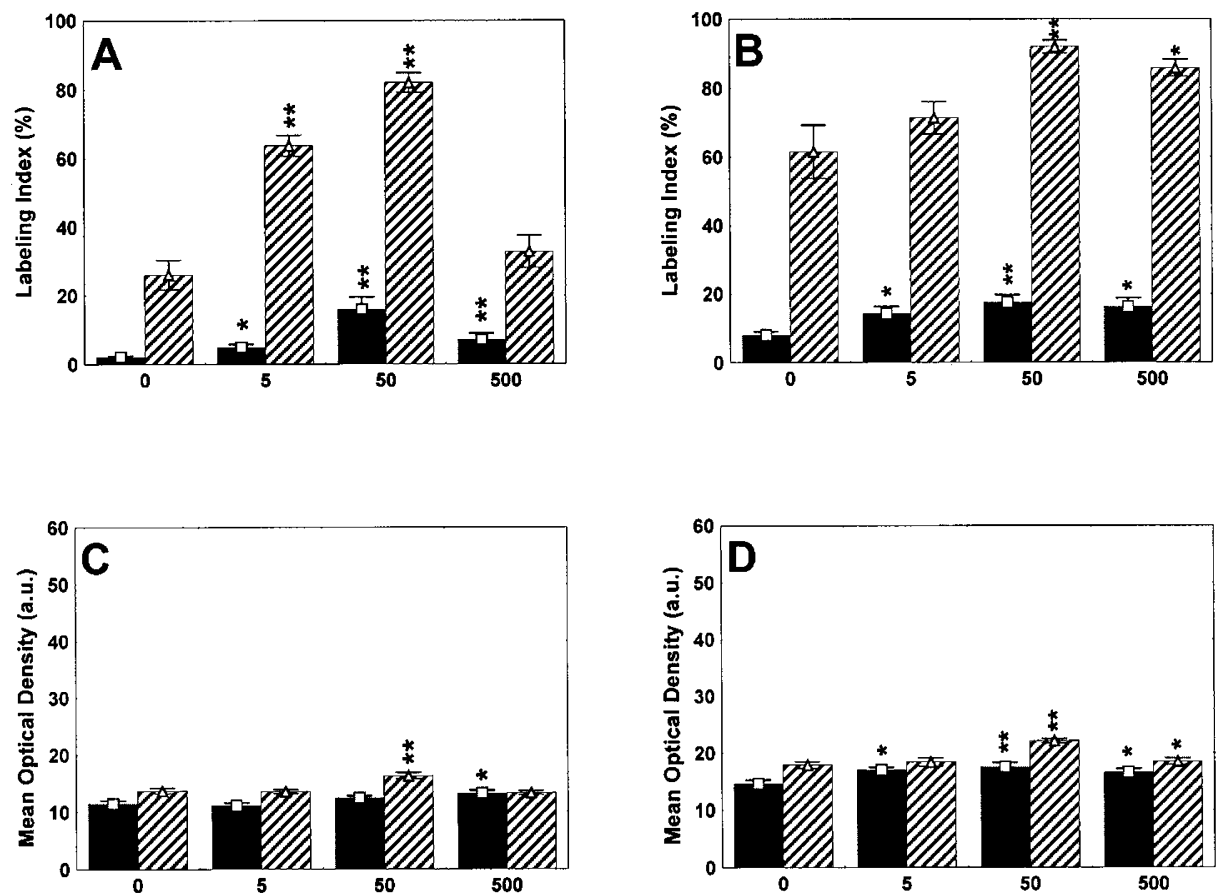

Cathepsin D
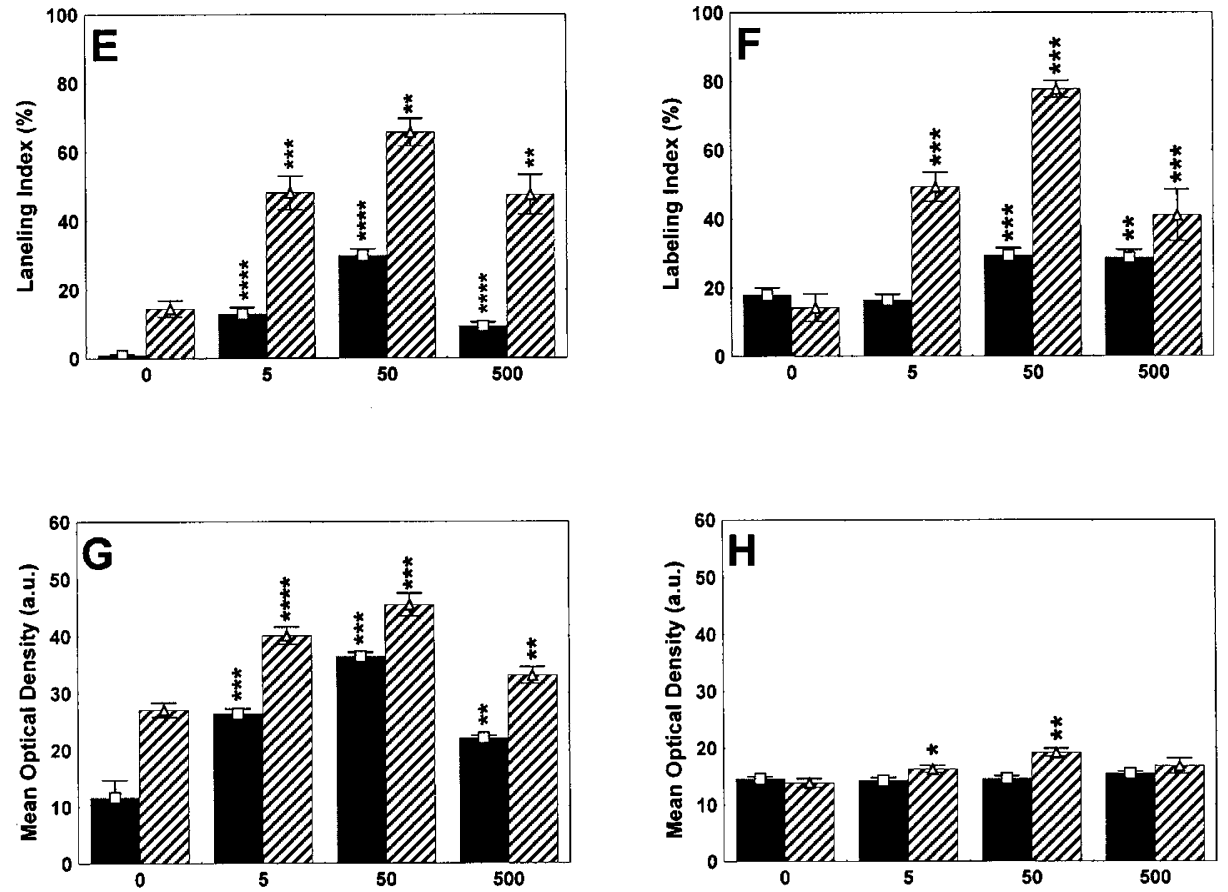

Figure 1.

Effects of prolactin on the immunohistochemical expression of cathepsin $B$ and $D$ in minor salivary glands obtained from a healthy subject $(A, C, E$ and $G)$ and from a patient with Sjögren's syndrome $(B, D, F$ and $H)$. The minor salivary glands were maintained under organotypic culture conditions for 24 hours in the absence $(0)$ or presence of 5,50 , or $500 \mathrm{ng} / \mathrm{ml}$ human prolactin. Cathepsin $\mathrm{B}(A$ to $D)$ and $\mathrm{D}(E$ to $H)$ immunoreactivity were quantified by means of computer-assisted microscopy on conventional histological slides obtained from these organotypic cultures and immunostained with the antibodies characterized in Figure 3 and its legend. The labeling index variable represents the percentage of immunohistochemically positive cells for a given antibody, and the mean optical density variable denotes staining intensity, ie, the cathepsin B or D concentration. Twenty acini (large dark bars) and ten ducts (large hatched bars) were analyzed in each experimental condition. The data are presented as means (large bars) \pm SEM (thin bars). Mann-Whitney test: ${ }^{*} p<0.05 ;{ }^{* *} p<0.01 ;{ }^{* * *} p<0.001$; and ${ }^{* * * *} p<0.0001$. 


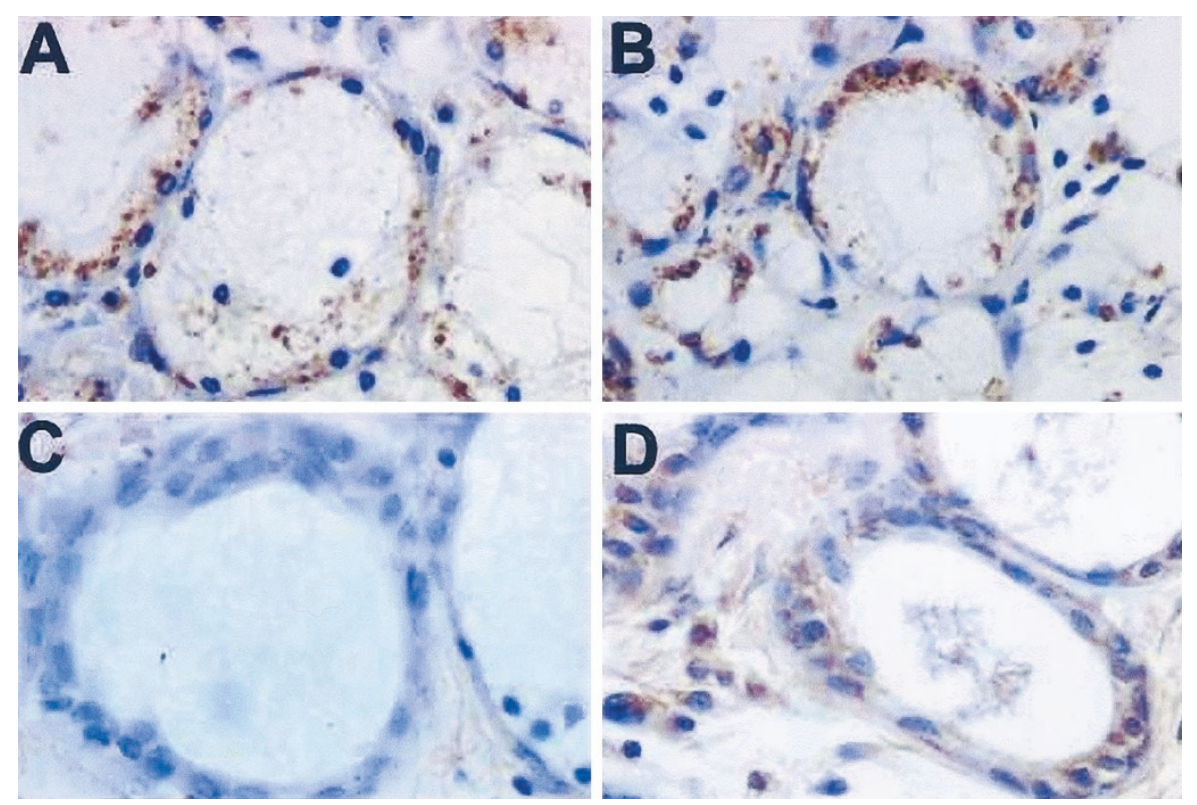

Figure 2.

Immunohistochemical illustrations of the expression of cathepsin B and D in human minor salivary glands (MSGs). $A$ and $B$, Cathepsin D expression in MSGs maintained for 24 hours under organotypic culture conditions in the absence $(A, G \times 40)$ or presence of $50 \mathrm{ng} / \mathrm{ml}$ prolactin $(B, G \times 40)$. $C$ and $D$, Cathepsin $B$ expression in MSGs maintained for 24 hours under organotypic culture conditions in the absence $(C, G \times 40)$ or presence of $50 \mathrm{ng} / \mathrm{ml}$ prolactin $(D, \mathrm{G} \times 40)$.

\section{Identification of Cathepsins B and D mRNAs}

Figure 4A illustrates the RT-PCR-related data for the cathepsin B and D transcripts in three SS MSGs (SS) and three control glands (CT). Cathepsin B mRNA was present in one of three control glands and in all three SS MSGs. Cathepsin D mRNA was present in two of three control glands and in all three SS MSGs.

Figure 4B illustrates the RT-PCR-related data for one minor salivary control gland cultured for 12 hours in both the presence $(+)$ and the absence $(-)$ of 50 $\mathrm{ng} / \mathrm{ml}$ prolactin. Although cathepsin B, but not cathep$\sin \mathrm{D}$, mRNA was absent in the control subject in absence of prolactin, very high levels of both cathepsin B and D mRNAs appeared after this culture in the presence of $50 \mathrm{ng} / \mathrm{ml}$ prolactin for 24 hours. In the MSGs of an SS patient cultured under the same experimental conditions, high levels of both cathepsin $B$ and $D$ mRNAs were observed in both control and the prolactin-treated conditions.

\section{Prolactin-Induced Effects on Immunohistochemical Cathepsin B and D Expression in MSGs of Control Subjects and Patients with SS}

The prolactin-induced effects on the immunohistochemical expression of cathepsins B and D in the acini and ducts of minor salivary glands maintained for 24 hours under organotypic conditions were characterized at three distinct doses $(5,50$, and $500 \mathrm{ng} / \mathrm{ml})$ in four control subjects and four patients with SS. The data obtained for the four control subjects were similar, as was also the case for the four patients with SS (data not shown). Therefore, for the sake of clarity in the presentation of the data, we will give those for one control subject and one SS patient only. Figure 1, A, C,
$\mathrm{E}$, and $\mathrm{G}$ refer to the control subject, and Figure 1, B, $D, E$, and $H$ refer to the patient with SS. The data indicate that markedly more cells expressed both cathepsin $B$ and $D$ in the ducts (the hatched bars in Fig. 1) than in the acini (dark bars) in both the control subject (Fig. 1, A and E) and the patient with SS (Fig. $1, B$ and F). Prolactin significantly increased the percentages of both cathepsin B and D immunopositive cells in a bell-shaped dose-dependent curve in both the control subject (Fig. 1, A and E) and the patient with SS (Fig. 1, B and F). Although less pronounced, similar data were obtained for the acini (Fig. 1, A and $B, E$ and $F$ ). The prolactin influence at the level of the cathepsin B immunohistochemical intensity (Fig. 1, C and D) was similar to what was observed for the percentage of cathepsin B immunopositive cells (Fig. $1, A$ and $B$ ). Prolactin markedly increased cathepsin D staining intensity in the control subject (Fig. 1G), while it did so only slightly in the case of SS patient (Fig. 1H). These features were typical of the 8 series of MSGs under study (data not shown). These data therefore suggest that MSGs of patients with SS are less reactive to prolactin in terms of cathepsin $D$ secretion because of the exhaustion of the system caused by the prolactin neosynthesis in these patients with SS, as explained in the "Discussion" section.

Figure 5 shows that cathepsin B immunoreactivity was also significantly increased in infiltrating mononuclear cells by prolactin treatment. No such significant prolactin-induced increase in cathepsin D-immunopositive infiltrating cells was observed.

\section{Discussion}

Recent studies of murine-nonobese diabetic (NOD), nonobese diabetic/severe combined immune-deficient 


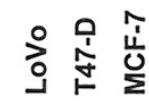

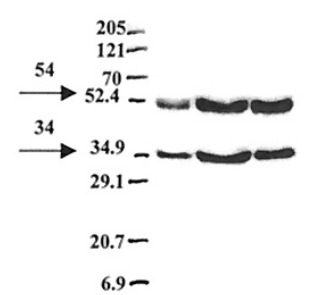

Cathepsin D

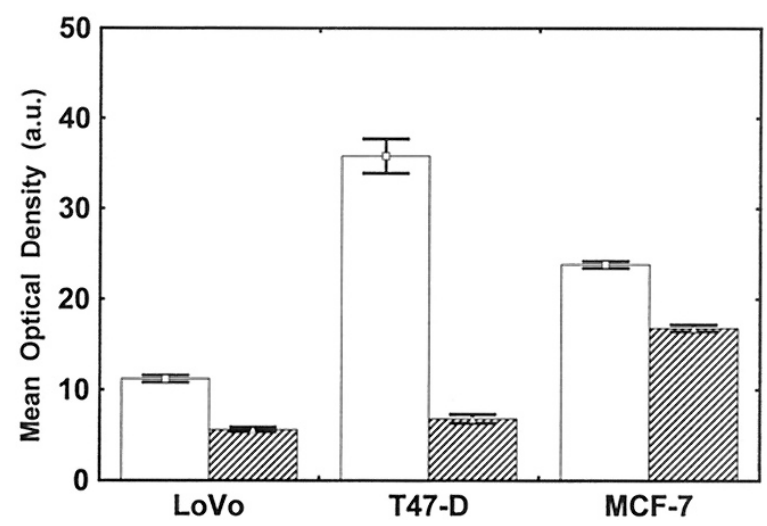

Figure 3.

Characterization by means of western blot analysis of the specificities of the anticathepsin $B$ and $D$ antibodies used in the present study (upper part of the figure). The cell lines used to test the specificity included the human LoVo colon and the T47-D and MCF-7 breast cancer cell lines. The lower part of the figure illustrates the data obtained by means of the computer-assisted microscope analysis of LoVo, T47-D, and MCF-7 cells submitted to standard immunohistochemical procedures with the same antibodies as those used for the western blot analysis. The mean optical density denotes staining intensity. The data are presented as means (large hatched bars for cathepsin B and large open bars for cathepsin D) \pm SEM calculated on 10 distinct samples, with each sample containing between 100 and 200 cells.

(NOD-Scid)_SS models and of patients with SS indicate that before the appearance of glandular infiltrating lymphocytes, the aberrant expression of proteases occurs in the saliva and gland lysates (Hanemaaijer et al, 1998; Konttinen et al, 1994; Robinson et al, 1997). Acinarprogrammed cell death in the submandibular gland of NOD-Scid mice appears to be independent of the lymphocyte infiltration (Robinson et al, 1996).

We recently showed that, although prolactin was neosynthesized in the acinar cells of minor salivary glands of patients with SS, this feature was not observed in control subjects (Steinfeld et al, 2000). In addition, the expression of prolactin was higher in SS patients with clinical extraglandular manifestations than in SS patients without these manifestations. Prolactin levels were positively correlated with the production of autoantibodies Ro and La nuclear proteins (Steinfeld et al, 2000). In the present study, we postulate a working hypothesis that the continuous prolactin neosynthesis in minor salivary glands of SS patients, but not in those of healthy subjects, might modulate the level of expression of some proteases and so lead to a progressive destruction of the glan-
A

SS CT CT CT SS SS

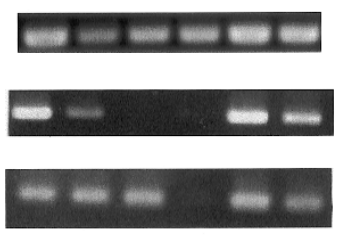

Figure 4.

Identification of cathepsin $B$ and $D$ mRNAs in minor salivary glands by means of RT-PCR technique. A, Illustrates the expression of cathepsin B and D mRNAs in the minor salivary glands of three healthy control subjects (CT) and three patients with Sjögren's syndrome (SS). B, Illustrates the expression of cathepsin $B$ and $D$ mRNAs in minor salivary glands (of one healthy control subject and one SS patient), which were maintained under organotypic culture conditions for 12 hours in the absence $(-)$ or presence $(+)$ of $50 \mathrm{ng} / \mathrm{ml}$ human prolactin.

dular epithelial cells because of this vicious circle. We chose to target cysteine and aspartic proteinases for the following reasons. Firstly, cathepsin B and D play major roles in the proteolytic cascade (Mort and Buttle, 1997), in apoptosis (Roberts et al, 1999) and in processing antigen (Yang et al, 1999). Prolactin is reported to regulate protein synthesis in animal salivary glands (Sabbadini and Berczi, 1995). In addition, several investigators have reported that prolactin may induce the overexpression of proteinases in the synovial cells of patients with rheumatoid arthritis (Nagafuchi et al, 1999) or during preovulatory peaks (Goto et al, 1999; Hirsch et al, 1999), ie, in a strong prolactin environment. Lastly, Azuma et al (1997) have reported an excessive metalloproteinase- 2 production by human salivary gland acinar cells in response to cytokines.

The present study shows that glandular epithelial cells in minor salivary glands of SS patients markedly express cathepsin D. This observation was made on the basis of both the biopsies obtained from routine diagnostic procedures and the glands maintained ex vivo under organotypic culture conditions. With respect to cathepsin $B$, whereas no expression was found in the routine biopsies, a slight expression was observed in the organotypic cultures. This feature suggests that cathepsin B expression could be repressed in vivo and that, once MSGs are removed and cultured in vitro, the inhibitory mechanism(s) no longer operate(s). Our data revealed that, in SS patients as well as in healthy controls, prolactin very significantly up-regulated the expression of both cathepsin B and $D$ in a dose-dependent manner and following a bellshaped curve. These data therefore validate our working hypothesis. Indeed, since we show that prolactin is neosynthesized in the glandular cells of the MSGs of patients with SS, and not in those of healthy controls, this neosynthesized prolactin is therefore able to stimulate the continuous expression of both cathepsins $B$ and $D$ and this, in turn, will bring their proteolytic activities into play. This feature is not present in 

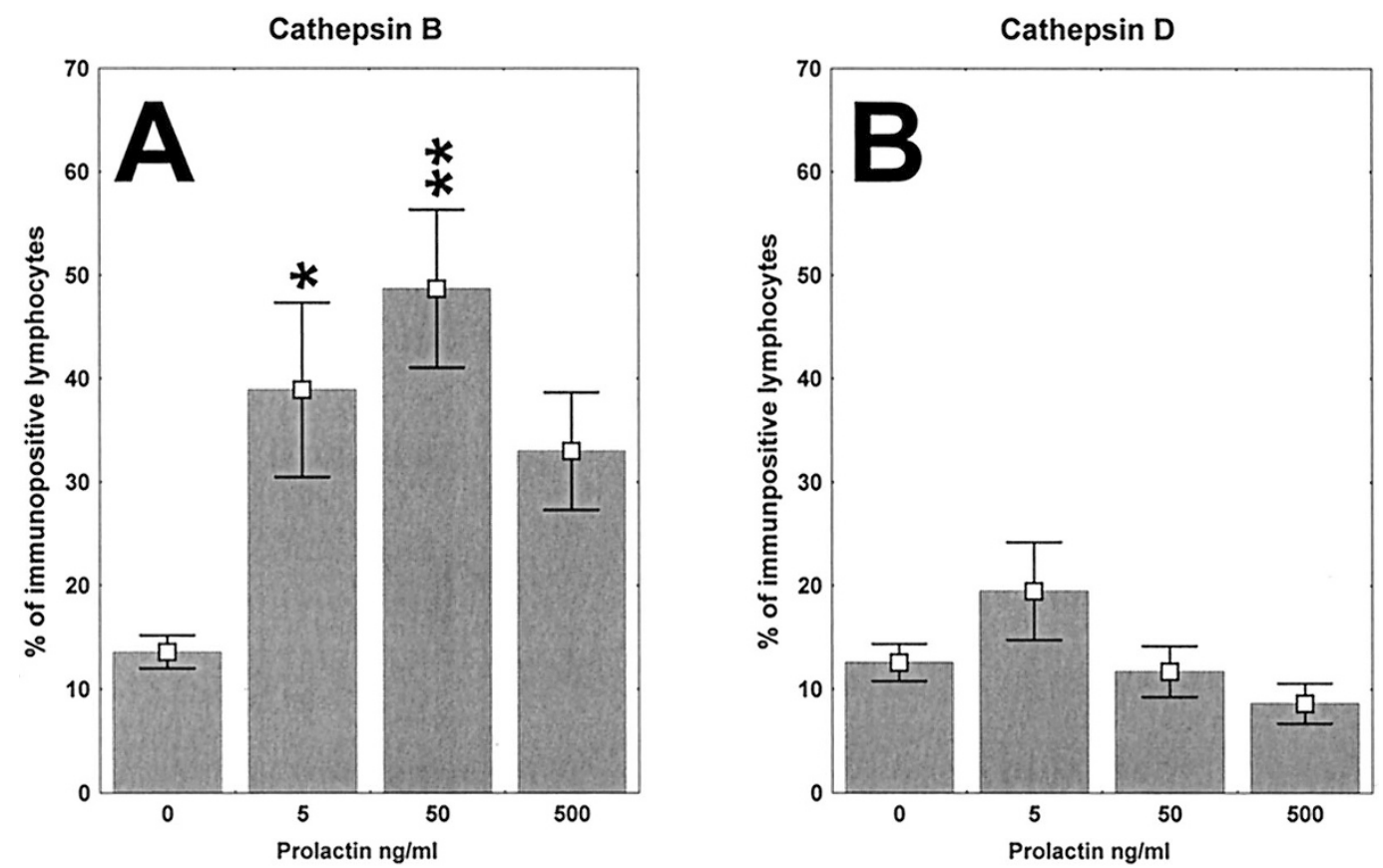

Figure 5 .

Effects of human prolactin on the immunohistochemical expression of cathepsin B and D in infiltrating mononuclear cells analyzed in the experimental conditions detailed in Figure 1 and its legend. Percentage of cathepsin B- and D-immunopositive mononuclear cells in total infiltrating cells with various concentrations of exogenous prolactin. Mean \pm SEM. Mann-Whitney test: ${ }^{\star} p<0.05 ;{ }^{* *} p<0.01$.

healthy subjects because there is no neosynthesis of prolactin. The data that we obtained here should be included in a more general context indicating that cathepsins B and D are involved in the pathology of chronic inflammatory diseases of the airways and joints, and in cancer (Mort and Buttle, 1997). The up-regulation and altered localization of cathepsins have been correlated with many cancers (Frosch et al, 1999). In normal epithelial cells, cathepsin B is localized into lysosomes, which are found in the perinuclear region, but localization is altered in tumors (Frosch et al, 1999). These alterations include secretion and localization on the cell surface, thus indicating a role for this protease in the degradation of extracellular matrix and basement membrane proteins. In the SS epithelial cells, cathepsin B was mainly located in the basal region of the cell.

Whether or not prolactin acts directly or indirectly at the level of the promotors of cathepsin B and D genes is still unknown. What is known is that Sjögren's syndrome occurs almost exclusively in women, and the influences of sex hormones and the hypothalamicpituitary axis are already well established in the pathophysiology of the Sjögren's syndrome (Johnson et al, 1998). Furthermore, androgens are known to decrease the activity of cathepsin D (Tanabe et al, 1982), and $17 \beta$-estradiol may induce cathepsin D gene expression (Cavaillès et al, 1993). Frosch et al (1999) have reported that the E-box is a regulatory element for the promoter region of cathepsin $\mathrm{B}$ gene. This E-box coordinates ovine prolactin transactivation (Liang et al, 1999).

The present data also revealed that infiltrating mononuclear cells in the MSGs of SS patients, when cultured in the presence of prolactin, showed an increased cathepsin B-immunoreactivity compared with the control condition. These findings suggest that the neosynthesized prolactin in the MSGs of patients with SS could modulate the biological functions of these infiltrating cells. Hyperprolactinemia has already been shown to be associated with a higher incidence of autoantibodies (Allen et al, 1996; Gutiérrez et al, 1996). One of the most frequent immunological dysregulations in patients with Sjögren's syndrome is the production of autoantibodies against the Ro and La nuclear protein. Salivary epithelial cells normally do not express these proteins (Peek et al, 1993). However, viral infection and cytokines lead to a significant Ro and La expression in salivary cells (Clark et al, 1994). Prolactin promotes the growth-related gene mRNA (Neidhart, 1998), and prolactin receptors are members of the hematopoietic/cytokine receptor family that are also present on the lymphocyte surface (Bole-Feysot et al, 1998). This type of receptor induces tyrosine phosphorylation by signaling through a Janus family kinase (JAK2) and transmission proteins belonging to the Stat5 family (Bole-Feysot et al, 1998). Stat5 is involved in the signal transduction of various cytokines and growth factors including interleukin-6 (IL-6), which is reported to be high in the saliva of SS patients (Grisius et al, 1996). In addition, IL-6 is an important factor in the production of immunoglobulin $M(\lg M)$ and immunoglobulin $G$ (IgG) (Kishimoto and Hirano, 1988). A recent study (Yang et al, 1999) has provided direct support for the thesis that human leukocyte antigen (HLA) class II molecules and cathepsins can provoke autoantigen presentation in epithelial cells. It seems reasonable to suggest that an 
association between prolactin and autoantibodies may be mediated by cathepsin overproduction.

All the data obtained in the present study therefore suggest that the prolactin neosynthesis, which occurs for still unknown reasons in the MSGs of patients with Sjögren's syndrome, could play a significant part in the destruction of acinar structures through the activation of proteinases, including at least cathepsins $B$ and D. New experiments are under investigation to characterize these prolactin-mediated effects on metalloproteinase expression in the MSGs of patients with SS.

\section{Materials and Methods}

\section{Patients and Controls}

Thirty patients (26 women and 4 men; mean age, $53 \pm$ 8 years) with Sjögren's syndrome were included in the study. Diagnosis of SS was based on both the San Diego (Fox et al, 1986b) and the European Community classification criteria (Vitali et al, 1993). Fourteen patients exhibiting secondary SS met the criteria for rheumatoid arthritis (Arnett et al, 1988). Antinuclear antibodies were present in all the patients: $82 \%$ positive anti-Ro/SSA antibody and 43\% positive anti-Ro/ SSA and anti-La/SSB antibodies. Fifteen healthy volunteers (14 women and 1 man; mean age, $51 \pm 6$ years) served as a healthy control group.

\section{Determination of Antinuclear Antibodies}

An indirect immunofluorescence procedure using Hep.2000 cell substrates was employed to detect the presence and titer of antinuclear antibody (Immunoconcept, Sacramento, California). Anti-Ro/SSA and anti-La/SSB antibodies were detected by means of ELISA (INOVA Diagnostics, San Diego, California).

\section{Western Blot Analysis of Cathepsin B and D}

Three human cancer cell lines were used to characterize the specificity of the anticathepsin B and anticathepsin D antibodies used in the present work. These cell lines were obtained from the American Type Culture Collection (ATCC, Manassas, Virginia) and included the LoVo (ATCC code CCL229) colon and the T47-D (ATCC code HTB133) and MCF-7 (ATCC code HTB22) breast cancer cell lines. The cells were cultured at $37^{\circ} \mathrm{C}$ in sealed (airtight) Falcon plastic dishes (Nunc, Gibco, Merelbeke, Belgium) containing Eagle's minimal essential medium (MEM, Gibco) supplemented with $10 \%$ fetal calf serum (FCS). All the media were supplemented with a mixture of $0.6 \mathrm{mg} / \mathrm{ml} \mathrm{glu-}$ tamine (Gibco), $200 \mathrm{lU} / \mathrm{ml}$ penicillin (Gibco), $200 \mathrm{lU} / \mathrm{ml}$ streptomycin (Gibco), and $0.1 \mathrm{mg} / \mathrm{ml}$ gentamycin (Gibco). The FCS was hot-inactivated for 1 hour at $56^{\circ} \mathrm{C}$.

Cell extracts were prepared by the sonication of scrapped subconfluent cells in PBS containing $1 \mathrm{~mm}$ phenyl methyl sulfonyl fluoride (PMSF) and $10 \mu \mathrm{g} / \mathrm{ml}$ aprotinin. Cell lysates containing $10 \mu \mathrm{g} / \mathrm{ml}$ of proteins, as evaluated by bicinchoninic acid (BCA) protein as- say (Pierce, Polylabo, Antwerpen, Belgium), were loaded in each lane of a $12 \%$ polyacrylamide gel under denaturing and reductive conditions. After electrophoresis, the proteins were transferred onto a Polyscreen PVDF membrane (NEN Life Science Products, Boston, Massachusetts) by tank blotting. Cathepsin B and $D$ proteins were further immunodetected by affinity-purified mouse monoclonal antibody for cathepsin B (clone Ab-3; Oncogene Research Products, Cambridge, Massachusetts) and rabbit polyclonal antibody for cathepsin D (clone Ab-1; Oncogene Research Products) in conjunction with goat antirabbit or antimouse immunoglobulin $\mathrm{G}$ conjugated with horseradish peroxidase $(0.2 \mu \mathrm{g} / \mathrm{ml}$; NEN). Control experiments included the omission of the incubation step with the anticathepsin B or the anticathepsin D antibody (negative control).

\section{RT-PCR of Cathepsin B and D}

Total RNA from the control subjects and the SS patients MSGs was extracted using the TriPure Isolation Reagent (Boehringer, Mannheim, Germany). Reverse transcription and PCR were performed on 100 ng of total RNA in a single-tube reaction using the Superscript One-Step RT-PCR system (Gibco BRL Life Technologies, Eragny, France). For cathepsin B and $D$ and glyceraldehyde-3-phosphate dehydrogenase (GAPDH), the specific primers used for the RT and PCR reactions were respectively: 5'-CTGAAGGTTGCAACTTCTGGAC-3', 5'-GTGCTTCACAGTCGTCTTC-3', and 5'-CGGAGTCAACGGATTTGGTCGTA$\mathrm{T}^{\prime}$ as forward primers, and 5'-TTCGATTCCGCAGTGATCCTG-3', 5'-GAGCCATAGTGGATGTCAAAC-3', and 5'-AGCCTTCTCCATGGTGGTGAAGAC-3' as reverse primers. All RT-PCR were performed with $100 \mathrm{ng}$ of forward and reverse primers in an Eppendorf Mastercycler Personal thermocycler (Eppendorf, Hamburg, Germany) using the following conditions: 35 cycles of $50^{\circ} \mathrm{C}$ for 30 minutes, $94^{\circ} \mathrm{C}$ for 2 minutes, $94^{\circ} \mathrm{C}$ for 30 seconds, $55^{\circ} \mathrm{C}$ for 30 seconds, $70^{\circ} \mathrm{C}$ for 1 minute; then $70^{\circ} \mathrm{C}$ for 10 minutes; and rapid cooling to $4^{\circ} \mathrm{C}$. Amplified products (500 bp for cathepsin B, 172 bp for cathepsin D, and 306 bp for GAPDH) were electrophoresed on a $2 \%$ agarose gel stained with ethidium bromide.

\section{Organotypical Minor Salivary Gland Cultures}

After informed consent had been obtained from each of the persons under study, four MSGs (lower lip) were biopsied from each of the eight persons, ie, four patients with SS and four healthy volunteers. The glands were maintained under organotypic culture conditions in a manner identical to the methodology described for human brain (Camby et al, 1996) and colon (Philippart et al, 2000) tumors. Briefly, after removal, each MSG was rinsed twice in MEM and immediately cut in half. To overcome the problem of biological heterogeneity, at least in part, two halves of two different MSGs taken from the same person were cultured for 24 hours in a given experimental condi- 
tion. Four experimental conditions were investigated for each of the four SS patients and the four control subjects. These four experimental conditions included the absence of prolactin (control condition) or the addition of either 5,50 , or $500 \mathrm{ng}$ prolactin/ml MEM. Human prolactin was obtained from Sigma-Aldrich (Belgium). After a 24-hour period of in vitro culture incubation, the two halves of the MSGs were fixed for 4 days in buffered formalin and processed for paraffin embedding. Five- $\mu \mathrm{m}$-thick sections were cut from each paraffin block containing the two half-MSGs. These sections were submitted to quantitative immunohistochemistry, as detailed below.

In addition to the eight series of four MSGs used for quantitative immunohistochemistry, six additional series of two minor salivary glands (three from SS patients and three from healthy controls) were processed as detailed above for RT-PCR analysis. The two experimental conditions included the absence (control) versus the presence of $50 \mathrm{ng} / \mathrm{ml}$ of prolactin for 12 hours in the culture media.

\section{Quantitative Immunohistochemistry for Cathepsins $B$ and $D$}

Three sections (5- $\mu \mathrm{m}$ thick) taken from each experimental condition were subjected to processing with the different histochemical probes and kit reagents under study. The anticathepsin B (dilution 1:100) and anticathepsin D (dilution 1:100) antibodies used for these experiments were as detailed for the western blot analysis. Incubation with antibodies was carried out at $25 \pm 1^{\circ} \mathrm{C}$ for 120 minutes. The extent of the specifically bound antibodies was visualized by avidin-biotin-peroxidase complex (ABC) kit reagents (Vector Labs, Burlingame, California), with diaminobenzidine $/ \mathrm{H}_{2} \mathrm{O}_{2}$ as the chromogenic substrate. A negative control was performed for each experimental condition. It consisted of the omission of the incubation step with the primary antibody to verify the absence of any staining by unspecific reagent binding. Counterstaining with hematoxylin concluded the procedure.

A semi-quantitative estimation of the immunohistochemical cathepsin B and D staining was carried out for the routine biopsies as detailed previously for lectin histochemistry in meningiomas (Salmon et al, 1996). This method is based on the precise estimation of both the staining intensity $(\mathrm{SI})$ of each probe and the relative abundance of immunoreactive cells (labeling index, LI) among the acinar and ductal epithelial cells and the infiltrating mononuclear cells of MSG biopsies. The positive cells in each section were counted field by field, with at least 20 fields $(\times 25)$ per specimen. The percentage of positive cells was subjectively divided into four grades. The different grades included sections containing no positive cells (-), $0 \%$ to $25 \%$ of positive $(+), 25 \%$ to $50 \%$ of positive $(++)$, and $>50 \%$ of positive $(+++)$ cells. The staining intensity (assessed in the histological fields used for the assessment of the labeling index) was graded 0 (absence of staining or staining equivalent to background staining in the negative control), 1 (weak to moderate staining), or 2 (intense staining).

Quantitative analysis of cathepsin B and D expression in the organotypic cultures of minor salivary glands submitted or unsubmitted to prolactin was carried out by means of computer-assisted microscopy as detailed elsewhere (Steinfeld et al, 1999). Computer-assisted microscopy refers to the SAMBA 2005 system (UNILOG, Grenoble, France) equipped with an Olympus BX50 microscope used at a $\times 20$ magnification (aperture, 0.50). Two variables were computed. The labeling index (LI) refers to the percentage of tissue area specifically stained by a histochemical probe. The mean optical density (MOD) denotes staining intensity. The computer-assisted microscope and related quantitative analyses were standardized as follows. A negative histological control slide (from which the primary antibody was omitted) was analyzed for each experimental condition under study. The software used on the computer-assisted microscope automatically subtracted the LI and MOD values of the negative control sample from each of the two positive samples available for each experimental condition. Specific software applications were included in the computer assisting the microscope in order to check any inherent shading in the chargecoupled device (CCD) camera-based systems, the glare phenomenon, and the level of linear precision. The shading and glare were checked each week. The monitoring procedure installed on our computerassisted microscope showed that neither shading, glare, nor linearity significantly modified our results (data not shown). Twenty acini and ten ducts were analyzed in each experimental condition.

\section{Statistical Analysis}

The Pearson $\chi^{2}$ and Mann-Whitney tests were used to evaluate the statistical differences between healthy control subjects and patients with Sjögren's syndrome and each probe expression (clearly estimated in the acinar, ductal epithelial, and mononuclear cells by means of the $\mathrm{LI}$ and SI variables). All the statistical analyses were carried out using the Statistica software (Statsoft, Tulsa, Oklahoma).

\section{References}

Adamson TC III, Fox RI, Frisman DM, and Howell FV (1983). Immunohistologic analysis of lymphoid infiltrates in primary Sjögren's syndrome using monoclonal antibodies. J Immunol 130:203-208.

Allen SH, Sharp GC, Wang G, Conley C, Takeda Y, Conroy SE, and Walker SE (1996). Prolactin levels and antinuclear antibody profiles in women tested for connective tissue disease. Lupus 5:30-37.

Arnett FC, Edworthy SM, Bloch DA, McShane DJ, Fries JF, Cooper NS, Healey LA, Kaplan SR, Liang MH, and Luthra HS (1988). The American Rheumatism Association 1987 revised criteria for the classification of rheumatoid arthritis. Arthritis Rheum 31:315-324. 
Azuma M, Motegi K, Aota K, Hayashi Y, and Sato M (1997). Role of cytokines in the destruction of acinar structure in Sjögren's syndrome salivary glands. Lab Invest 77:269-280.

Bole-Feysot C, Goffin V, Edery M, Binart N, and Kelly PA (1998). Prolactin (PRL) and its receptor: actions, signal transduction pathways and phenotypes observed in $P R L$ receptor knockout mice. Endocr Rev 19:225-268.

Camby I, Salmon I, Danguy A, Pasteels JL, Brotchi J, Martinez J, and Kiss R (1996). Influence of gastrin on human astrocytic tumor cell proliferation. J Natl Cancer Inst 88:594600.

Cavaillès V, Augereau P, and Rochefort H (1993). Cathepsin $D$ gene is controlled by a mixed promoter, and estrogens stimulate only TATA-dependent transcription in breast cancer cells. Proc Natl Acad Sci USA 90:203-207.

Chapman HA, Riese RJ, and Shi GP (1997). Emerging roles for cysteine proteases in human biology. Annu Rev Physiol 59:63-88.

Clark DA, Lamey PJ, Jarrett RF, and Onions DE (1994). A model to study viral and cytokine involvement in Sjögren's syndrome. Autoimmunity 18:7-14.

Davidson HW and Watts C (1989). Epitope-directed processing of specific antigen by B lymphocytes. J Cell Biol 109:85-92.

Deiss LP, Galinka H, Berissi H, Cohen O, and Kimchi A (1996). Cathepsin D protease mediates programmed cell death induced by interferon- $\gamma$, Fas/APO- 1 and TNF- $\alpha$. EMBO J 10:3861-3870.

Foster HA, Stephenson D, Walker G, Cavanagh CK, and Griffiths I (1993). Linkage studies of HLA and primary Sjögren's syndrome in multicase families. Arthritis Rheum 36:473-484.

Fox RI, Bumol T, Fantozzi R, Bone R, and Schreiber R (1986a). Expression of histocompatibility antigen HLA-DR by salivary gland epithelial cells in Sjögren's syndrome. Arthritis Rheum 29:1105-1111.

Fox RI, Robinson CA, Curd JG, Kozin F, and Howell FV (1986b). Sjögren's syndrome: Proposed criteria for classification. Arthritis Rheum 29:577-585.

Fox RI and Kang HI (1992). Pathogenesis of Sjögren's syndrome. Rheum Dis Clin North Am 18:517-538.

Frosch BA, Berquin I, Emmert-Buck MR, Moin K, and Sloane BF (1999). Molecular regulation, membrane association and secretion of tumor cathepsin B. APMIS 107:28-37.

Garcia-Caballero T, Morel G, Gallego R, Fraga M, Pintos E, Gago D, Vonderhaar BK, and Beiras A (1996). Cellular distribution of prolactin receptors in human digestive tissues. $\mathrm{J}$ Clin Endocrinol Metab 8:1861-1886.

Goto T, Endo T, Henmi H, Kitajima Y, Nishikawa A, Manase K, Sato H, and Kudo R (1999). Gonadotrophin-releasing hormone agonist has the ability to induce increased matrix metalloproteinase (MMP)-2 and membrane type 1-MMP expression in corpora lutea, and structural luteolysis in rats. $J$ Endocrinol 161:393-402.

Gutiérrez MA, Molina JF, Jara LJ, Garcia C, Gutiérrez-Urena S, Cuellar MC, Gharavi A, and Espinoza LR (1996). Prolactininduced immunoglobulin and autoantibody production by peripheral blood mononuclear cells from systemic lupus erythematosus and normal individuals. Int Arch Allergy Immunol 109:229-235.
Grisius MM, Bermudez DK, and Fox PC (1996). Salivary and serum interleukin 6 in primary Sjögren' syndrome. J Rheumatol 24:1089-1091.

Hanemaaijer R, Visser $\mathrm{H}$, Konttinen YT, Koolwijk $\mathrm{P}$, and Verheijen JH (1998). A novel and simple immunocapture assay for determination of gelatinase-B (MMP-9) activities in biological fluids: Saliva from patients with Sjögren's syndrome contains increased latent and active gelatinase-B levels. Matrix Biol 17:657-665.

Hirsch B, Knoke I, Leonhardt S, Pitzel L, Jarry H, and Wuttke W (1999). Stimulation of matrix-metalloproteinase-1 and tissue inhibitor of metalloproteinase-1 gene expression in rats by the preovulatory prolactin peak. Eur J Endocrinol 140: 583-589.

Johnson EO, Vlachoyiannopoulos PG, Skopouli FN, Tzioufas AG, and Moutsopoulos HM (1998). Hypofunction of the stress axis in Sjögren's syndrome. J Rheumatol 25:1508-1514.

Kaslow HR, Guo Z, Warren DW, Wood RL, and Mircheff AK (1998). A method to study induction of autoimmunity in vitro: Co-culture of lacrimal cells and autologous immune system cells. Adv Exp Med Biol 438:583-589.

Kerttula TO, Collin P, Polvi A, Korpela M, Partanen J, and Mäki M (1996). Distinct immunologic features of Finnish Sjögren's syndrome patients with HLA alleles DRB1*0301, $\mathrm{DQA} 1{ }^{*} 0501$ and $\mathrm{DQB} 1{ }^{*} 0201$. Arthritis Rheum 39:1733-1739.

Kishimoto T and Hirano T (1988). Molecular regulation of $B$ lymphocyte response. Annu Rev Immunol 6:485-512.

Konttinen YT, Kangaspunta P, Lindy O, Takagi M, Sorsa T, Segerberg M, Tschesche H, and Eisen AZ (1994). Collagenase in Sjögren's syndrome. Ann Rheum Dis 53:836-839.

Liang R, Limesand SW, and Anthony RV (1999). Structure and transcriptional regulation of the ovine placental lactogen gene. Eur J Biochem 265:883-895.

Mizuochi T, Yee ST, Ksai M, Kakiuchi T, Muno D, and Kominami E (1994). Both cathepsin B and cathepsin D are necessary for processing of ovalbumin as well as for degradation of class II MHC invariant chain. Immunol Lett 43:189-193.

Mort JS and Buttle DJ (1997). Cathepsin B. Int J Biochem Cell Biol 29:715-720.

Nagafuchi H, Suzuki N, Kaneko A, Asai T, and Sakane T (1999). Prolactin locally produced by synovium infiltrating $\mathrm{T}$ lymphocytes induces excessive synovial cell functions in patients with rheumatoid arthritis. J Rheumatol 26:1890-1900.

Nishimura Y, Kawabata T, and Kato K (1988). Identification of latent procathepsins $B$ and $L$ in microsomal lumen: Characterization of enzymatic activation and proteolytic processing in vitro. Arch Biochem Biophys 261:64-71.

Neidhart M (1998). Prolactin in autoimmune diseases. Proc Soc Exp Biol Med 217:408-419.

Peek R, Prujin GJ, van der Kemp AJ, and van Venrooij WJ (1993). Subcellular distribution of Ro ribonucleoprotein complexes and their constituents. J Cell Sci 106:929-935.

Philippart P, Harper L, Chaboteaux C, Decaestecker C, Bronckart Y, Gordower L, Lesueur-Ginot L, Malonne H, Lavergne O, Bigg D, Mendes da Costa P, and Kiss R (2000). Homocamptothecin, an E-ring modified camptothecin, exerts more potent antiproliferative activity than other topoisomerase I inhibitors in human colon cancers obtained from surgery and maintained in vitro under histotypical culture conditions. Clin Cancer Res 6:1557-1562. 
Reveille JD and Arnett FC (1992). The immunogenetics of Sjögren's syndrome. Rheum Dis Clin North Am 101:748-756.

Rischmueller M, Lester S, Chen Z, Champion G, Van Den Berg R, Beer R, Coates T, McCluskey J, and Gordon T (1998). HLA class II phenotype controls diversification of the autoantibody response in primary Sjögren's syndrome. Clin Exp Immunol 111:365-371.

Roberts LR, Adjei PN, and Gores GJ (1999). Cathepsins as effector proteases in hepatocyte apoptosis. Cell Biochem Biophys 30:71-88.

Robinson CP, Yamachita S, Alford CE, Cooper C, Pichardo EL, Shah N, Peck AB, and Humphreys-Beher MG (1997). Elevated levels of cysteine protease activity in the saliva and salivary glands of non-obese diabetic (NOD) mouse model for Sjögren's syndrome. Proc Natl Acad Sci USA 94:57675771.

Robinson CP, Yamamoto H, Peck AB, and Humphreys-Beyer MG (1996). Genetically programmed development of salivary gland abnormalities in the NOD (nonobese diabetic)-scid mouse in the absence of detectable lymphocytic infiltration: A potential trigger for sialoadenitis in NOD mice. Clin Immunol Immunopathol 79:50-59.

Sabbadini E and Berczi I (1995). The submandibular gland: A key organ in the neuroimmunoregulatory network? Neuroimmunomodulation 2:184-202.

Salmon I, Camby I, Remmeling M, Rombaut F, Pastells JL, Brotchi J, Kiss R, and Danguy R (1996). Lectin histochemistry, ploidy level and proliferation indices in meningioma subtypes. Neuropathol Appl Neurobiol 22:68-76.

Scezi PB (1992). The aspartic proteases. Scand J Clin Lab Invest 52:5-22.
Steinfeld S, Penaloza A, Ribaï P, Decasetecker C, Danguy A, Gabius H-J, Salmon I, Appelboom T, and Kiss R (1999). $\mathrm{D}$-Mannose and $\mathrm{N}$-acetylglucosamine moieties and their respective binding sites in salivary glands of Sjögren's syndrome. J Rheumatol 26:833-841.

Steinfeld S, Rommes S, François C, Decaestecker C, Maho A, Appelboom T, Heizmann CW, Kiss R, and Pochet R (2000). Big prolactin $60 \mathrm{kDa}$ is overexpressed in salivary glandular epithelial cells from patients with Sjögren's syndrome. Lab Invest 80:239-247.

Tanabe ET, Lee C, and Grayhack JT (1982). Activities of cathepsin $\mathrm{D}$ in rat prostate during castration-induced involution. J Urol 127:826-828.

Vitali C, Bombardieri S, Moutsopoulos HM, Balestrieri G, Bencivelli W, Bernstein RM, Bjerrum KB, Braga S, Coll J, and de Vita S (1993). Preliminary criteria for the classification of Sjögren's syndrome. Results of a prospective concerted action supported by the European Community. Arthritis Rheum 36:340-347.

Wu AJ, Lafrenie RM, Park C, Apinhasmit W, Chen ZJ, Birkedal-Hansen H, Yamada KM, Stetler WG, and Baum BJ (1997). Modulation of MMP-2 (gelatinase A) and MMP-9 (gelatinase B) by interferon- $\gamma$ in a human salivary gland cell line. J Cell Physiol 171:117-124.

Yang $\mathrm{T}$, Zeng $\mathrm{H}$, Zhang J, Okamoto CT, Warren DW, Wood RL, Bachmann M, and Mircheff AK (1999). MHC class II molecules, cathepsins, and La/SSB proteins in lacrimal acinar cell endomembranes. Am J Physiol 277:C994-C1007. 